about $18 \% .{ }^{26} \mathrm{~A}$ particularly well-designed survey of 2,511 persons conducted in late 2001 found that DTCA television ads caused $30 \%$ of the respondents to ask their physician about the advertised drug, 29\% actually asked for a prescription, and $44 \%$ received the prescription, an ATR ratio of $13 \% .{ }^{27}$ A telephone survey of 943 adults in early 2002 found that $69 \%$ of the respondents who had asked their physician for a specific brandname drug had received the drug, 5\% said that a DTC advertisement had precipitated the physician visit, and 4\% said they visited the physician because they wanted to obtain the advertised drug. ${ }^{28}$

From a quality-of-care perspective, DTCA might have other effects. Among the aforementioned studies, about one third of respondents who had asked their physicians about a particular drug reported that they did not know the disease condition of the advertised and requested drug. Among 1,300 AARP members surveyed in May 2000, one third did not notice the small print in DTC advertisements regarding the side effects and risks of drugs. ${ }^{29}$ A survey of 1,601 persons conducted by Prevention magazine in September and October 2001 found that 49\% believed that DTC drug advertising contributed to tension between physicians and patients. ${ }^{30}$ In the aforementioned survey of 2,511 persons sponsored by the Kaiser Family Foundation, 25\% of the viewers of the television advertisement for montelukast believed, erroneously, that the tablet could be used to alleviate an acute exacerbation of asthma, and $70 \%$ of participants in the survey indicated that they learned little or nothing from watching the advertisements. ${ }^{31}$

\section{Measuring Outcomes of 3-Tier Copay Drug Benefit Plans}

The dramatic increase in drug benefit costs in the period beginning in 1998 and continuing through 2002 caused a very rapid uptake of the 3- and 4-tier copay drug benefit plan designs among private health benefit plans, including Medicare+Choice plans. Languishing among 2-tier copay and closed formulary drug plans for 6 to 7 years, ${ }^{32}$ health plans, PBMs, and employers embraced these multi-tier copay plans with new vigor in 1999 and thereafter. But are these "new" drug benefit designs healthful for consumers and for the U.S. health care system? To begin to answer these questions, we first need a common nomenclature to use in defining these plans.

Single copay plans were used early in the administration of third-party prescription drug plans because the price (allowable charge in third-party payer vernacular) was not known. In the period before 1980, electronic claims processing of prescription claims and the precision and accuracy that we have come to expect today did not exist. The adoption of electronic processing for prescription drug claims in the early 1980s and its widespread implementation after 1985 permitted reconsideration of member cost-share in plan design. By the end of the 1980s, 2-tier copay plans were common, and percentage cost-share drug plans were feasible and even practical. Today, there exists a dizzying array of drug benefit designs among health plans and self-insured employers. Specified dollar copayments are overlaid with coinsurance, sometimes with deductibles or benefit (dollar) maximums. There are 3-, 4-, and even 5-tier plans. Research on the effects of these plans on cost, utilization, member satisfaction, and medication adherence, as well as other outcomes, demands that we have a nomenclature to define drug benefit plan design. Terms such as "multi-tier" or "3-tier" are not sufficiently specific to permit effective communication among managed care pharmacists and interested parties. For example, a 3-tier copay design may have 2 copay amounts (tiers) for brand formulary drugs while another 3-tier copay design may have only one copay amount (tier) for formulary drugs (i.e., nonformulary drugs would be assigned to the thirdcopay tier). Most 3-, 4-, and 5-tier copay designs assign the lowest (tier-1) copay to generic drugs, but even this is not always true.

Thus far, there have been few reliable results produced from efforts to measure clinical, service (humanistic), or cost outcomes of the multi-tier-copay drug plan designs. ${ }^{33}$ In this issue of the Journal, Nair, Ganther, Valuck et al., report that 3-tier drug plan members had less favorable attitudes toward their plans compared to those in 2-tier plans. ${ }^{34}$ This work advances our inspection of the effects of 3-tier copay drug benefit plans versus 2-tier plans, but the results should be interpreted cautiously and the discussion evaluated critically. While the authors attempted to measure the effects of age as an independent variable, their study groups were dramatically different. The 2-tier copay group $(\mathrm{N}=2,316)$ had $11.7 \%$ of its members over age 65 versus $54.7 \%$ for the 3-tier copay group $(\mathrm{N}=1,499)$. Not surprisingly, higher out-of-pocket copayment costs are incurred by persons over age 65 due to higher prescription utilization. Also, only $10 \%$ of the tier- 2 plan members were enrolled in Medicare+Choice versus $61.4 \%$ of the tier-3 plan members. All Medicare+Choice members had a $\$ 1,000$ annual benefit maximum, a variable that would be expected to affect member attitudes, particularly for the members with chronic diseases that were the subjects in their study.

Managed care strives to obtain the same or better outcomes at lower cost, thereby creating the ability to restrain the absolute amount and relative increase in health care premiums. Lower premiums make care affordable to more persons. Higher premiums make insurance coverage affordable to fewer persons..$^{35}$ A significant increase in the cost of health care and health care coverage in 2002 and 2003 can be expected to result in an increase in the number of uninsured. U.S. Census Bureau figures, released September 30, 2002, showed that the nation's uninsured population grew $3.5 \%$ in 2001, from 39.8 million in 2000 to 41.2 million. ${ }^{36}$ Free health care would make rationing necessary. Cost sharing at the point of care reduces the cost of health care premiums and can be employed in multi-tier copayments to influence member choice of care (e.g., drug). Therefore, multi-tier copay plans represent quintessential managed care, maximum choice. It is unfortunate, but reparable, 
that many managed care drug plans overcharge members for generic drugs with copays of more than $\$ 5$ per 30 -day supply. For example, an announcement in mid-2002 trumpeted a program to promote generic drugs to physicians, pharmacists, and consumers but was associated with a 3-tier benefit design of $\$ 12$ (generic), \$20 (tier-2) and \$30 (tier-3) copays for a 30-day supply. ${ }^{37}$

The study by Nair, Ganther, Valuck, et al. adds to a thin literature on health plan member attitudes, other than satisfaction, related to prescription drug benefit plans. The study methods and interpretation of results should be reviewed carefully and critically. For example, the authors report statistically significant results that often appear to be an artifact of the large sample size and may have little if any practical significance, but, nevertheless, be of interest to some readers For example, the authors reported that 3-tier plan members compared to 2-tier plan members may be more likely to consult with friends or family members to obtain information related to the purchase of prescriptions, but not the pharmacist, or that 3-tier plan members may be more likely to obtain a second opinion from another physician. In all of these cases, the absolute differences in the mean scores are very small, less than 0.25 points on a 7-point scale. In survey research, ask 100 questions, and 5 will be statistically significant simply by chance, at an a priori $P$ value of 0.05. Survey enough respondents, and small differences in mean scores will produce statistically significant results.

\section{JMCP Peer Review and Editorial Process}

The quality of the Journal depends upon the collaborative work of authors, reviewers, and editors. Reviewers are often themselves authors, and more than 150 reviewers help to continuously improve the quality of the Journal. The bias management policy of the Journal is extensive and encompasses reviewers as well as authors. Members of the JMCP Editorial Advisory Board sometimes submit manuscripts for consideration, and these papers are treated no differently than any other manuscript.

All manuscripts submitted for consideration in the Journal undergo a prereview screen to protect reviewers from work associated with a paper that, due to a fundamental flaw in research design or insufficient relevance to readers, cannot be revised sufficiently to earn publication in the Journal . This prereview process is generally completed within 2 weeks of receipt of the manuscript. After passing the prereview process, each manuscript is sent to at least 3 independent reviewers, selected based upon expertise in one or more areas that are the principal subjects of the manuscript. All reviews are conducted under masking of author names and affiliations. Anonymity is the cornerstone of critical, scholarly review.

The JMCP bias management policy applies to all persons, regardless of their affiliation. In this issue of the Journal, the chairperson of the Editorial Advisory Board, Marvin D. Shepherd, PhD, collaborated with another researcher, Patricia Harrington, to write a subject review on the very timely matter of the transition of drugs from prescription to availability over-the- counter (OTC). In this case, 3 expert peer reviewers agreed unanimously that the manuscript should be published, and the authors revised the manuscript according to all reviewer suggestions. The mission of JMCP is to provide reliable and timely information to assist managed care pharmacists in their efforts to maximize value for money and improve the quality of patient care.

Frederic R. Curtiss, PhD, RPh, CEBS, Editor-in-Chief

\section{REFERENCES}

1. Winslow R, McGinley L, Adams C. States, insurers find prescriptions for high drug costs. Wall Street J. September 11, 2002:A1,A8.

2. Winslow R. Kaiser's experiment with generics. Wall Street J. September 11, 2002:A8.

3. Calabrese DC, Baldinger SL. Dose-optimization intervention yields significant drug cost savings. J Managed Care Pharm. 2002;8(2):146-51.

4. Gee M, Hasson NK, Hahn T, et al. Effects of a tablet-splitting program in patients taking HMG-CoA reductase inhibitors: analysis of clinical effects, patient satisfaction, compliance and cost avoidance. J Managed Care Pharm. 2002;8(6):453-58.

5. National Committee on Quality Assurance. The state of health care quality: Available at: http://www.ncqa.org/Communications/State\%200f\% 20Managed\%20Care/SOHCREPORT2002. Accessed October 3, 2002.

6. Expert Panel on Detection, Evaluation, and Treatment of High Blood Cholesterol in Adults. Executive summary of the third report of the National Cholesterol Education Program (NCEP) Expert Panel on Detection, Evaluation, and Treatment of High Blood Cholesterol in Adults (Adult Treatment Panel III.) JAMA. 2001;285(19):2486-97. Full ATP II guidelines available at: http://www.nhlbi.nih.gov/guidelines/cholesterol/index.htm. Accessed October 3, 2002.

7. Wolfe B, del Rio E, Weiss SL, et al. Validation of a single-patient drug trial methodology for personalized management of gastroesophageal reflux disease. J Managed Care Pharm. 2002;8(6):459-68.

8. Reuters Health. New York. May 16, 2002.

9. Multiple Sclerosis Council for Clinical Practice Guidelines. Disease-modifying therapies in multiple sclerosis. Evidence-based management strategies for disease-modifying therapies in multiple sclerosis. Paralyzed Veterans of America; 2001.

10. Lublin FE, Reingold SC. Defining the clinical course of multiple sclerosis: results of an international survey. Neurol. 1996;46:907-11.

11. Rudick RA, Cohen JA, Weinstork-Guttman B, et al. Management of multiple sclerosis. New Engl J Med. 1997;1604-11.

12. Drug Facts and Comparisons, Clinisphere version. Facts \& Comparisons. September 2002.

13. Ollendorf DA, Jilinskaia E, Oleen-Burkey M. Clinical and economic impact of glatiramer acetate versus beta interferon therapy among patients with multiple sclerosis in a managed care population. J Managed Care Pharm. 2002;8(6):469-76

14. Drug Facts and Comparisons, Clinisphere version. Facts \& Comparisons. September 2002.

15. www.fda.gov/OTC+Prilosec. Accessed October 10, 2002.

16. Harrington P, Shepherd MD. Analysis of the movement of prescription drugs to over-the-counter status. J Managed Care Pharm. 2002;8(6):499-508

17. Harris G. As a patent expires, drug firm lines up pricey alternative. Wall Street J. June 6, 2002:Al,Al0

18. Drug Price Competition and Patent Term Resotration Act (HatchWaxman), Public Law No. 97-417, 21 USC \$355(j) (1984).

19. Naik G. For AstraZeneca, ruling on patents will be critical. Wall Street J. September 10, 2002:C1,C3 